\title{
Conventional versus Unconventional Outsourcing
}

\author{
Jacques Touma \\ Lebanese American University, Beirut, Lebanon \\ Email: Jacques.touma@lau.edu.lb
}

How to cite this paper: Touma, J. (2020). Conventional versus Unconventional Outsourcing. American Journal of Industrial and Business Management, 10, 1812-1822. https://doi.org/10.4236/ajibm.2020.1012112

Received: November 16, 2020 Accepted: December 20, 2020

Published: December 23, 2020

Copyright $\odot 2020$ by author(s) and Scientific Research Publishing Inc. This work is licensed under the Creative Commons Attribution International License (CC BY 4.0).

http://creativecommons.org/licenses/by/4.0/ (c) (i) Open Access

\begin{abstract}
Today's world is becoming very competitive and companies are going the extra miles and revisiting their strategies to keep up and sustain competitive advantage. Companies are striving towards low cost, high-quality products delivering value to customers therefore a need to focus on core competencies is essential to create that value and minimize overheads. Capitalizing on know-how, brand equity management, customer and partner relationship management, today's companies drive for building long-term strategic ventures with selected partners in key markets. Companies are realizing the importance of adding value, reducing cost while delivering products to customers smoothly and efficiently therefore gaining market penetration, market development and product development which result in more market shares at minimum cost, better global presence, brand ownership in case of distributor partnership allocation. This study focuses on the many ways of conventional and unconventional outsourcing, to gain competitive advantage while pointing out where outsourcing can be of failure to some companies lacking strategic management. It also shows the importance of intelligent versus traditional outsourcing where factors such as cutting cost, streamlining the operations and creating partnerships have to be more revolving and consider more convergent and divergent thinking adding for instance innovation to cutting cost, or streamlining the value chain as a whole or adding trust based partnership not just an arm length.
\end{abstract}

\section{Keywords}

Outsourcing, Small Medium Enterprises (SME), Gap Analysis, Cost of Good Solds (GOGS), Just in Time (JIT)

\section{Conventional Outsourcing}

Outsourcing became a strategic choice and effective tool for companies to cut 
costs and focus on core competencies while gaining market shares through the right implementation and agreement with third party outsourcing.

In this paper, conventional outsourcing is referred to outsourcing support functions which can be service providers to the operations such as information technology, marketing and human resources to use capital and other resources in core functions. Although outsourcing support function is not simple yet companies can manage the risk factors considering they have the right strategy and implementation (Raiborn et al., 2009).

It has shown over the years that outsourcing has been a good strategy in corporate decision making, according to outsourcing Institute, companies scored $9 \%$ cost savings while performed an increase of $15 \%$ in quality and capacity on average through outsourcing (Elmuti et al., 1998).

Outsourcing these days include as well the need to touch on the administration functions to some extent, in addition to machines and equipment procurement, suppliers are being asked to perform certain certification related to the industry. They are involved in the work of subassemblies and any other requirement that can be performed with the help of technology, suppliers are accepting the job.

Subsequently, companies are effectively outsourcing tasks within operations handed to the suppliers when they ask them to perform additional tasks to complete certain operations for them. Also it all depends on the sector and the industry, for instance, it has been noticed that commodities are more likely to be produced overseas using certain technology to accommodate customers demand (Zelinski, 2018).

Globalization has its impact on companies today in outsourcing since there is a need for businesses to reach overseas providers throughout the world to partner with and get the products across. The importance of partnership helps companies to overcome complications related to compliance with country laws, sophisticated transportation systems, political conditions and understanding legal implications in different countries (Karthik, 2013b).

\subsection{Reasons and Benefits of Outsourcing}

Solid yet mutually fair agreements between the company and third party providers can reach gain in competitive advantage. There are benefits and reasons to long term outsourcing:

One main reason could be to allocate resources and employees for other purposes since companies are engaged in several activities by outsourcing some of these non-core activities could give additional advantage for these companies to use their resources widely and concentrate on the core business which is the most valuable asset to that company.

A second reason would be to minimize or share risks with the outsourcer coming from external factors such as governmental, legal and economic resulting from operating a business and keeping up with changes that happen during 
the course of business which can be expensive, challenging and taxing to the limited resources of that business.

A third reason would be research and development (re-engineering) since a lot of companies find that this department is under performing to standards and some don't have a solid existence in research to effectively implement a new product or service. In that case, the advantage of outsourcing a third solid provider distinguishes the benefits of reengineering (Elmuti et al., 1998).

Benefits to outsourcing include cost savings especially in the non-core functions for instance when dealing with offshore companies where you have a much lower pay scale and good quality output.

Another benefit when outsourcing is the expertise of the companies providing the outsource function in terms is using their infrastructure, technology and their employees in a way to spread the cost among all of its customers.

Additionally, metrics can be used to measure the performance of the outsourced functions, allowing companies to pay per performance rather than investing in long term resources that could be of burden in case of inefficiency of work performance (Raiborn et al., 2009).

Unavailability of resources can be a reason why companies outsource and that could be of a great advantage especially to companies that don't have the resources, cash or facility, keeping in mind the alternative in case the cost/benefit analysis shows that acquiring the process internally can be more profitable from all aspects. A good example for this reason is when an SME or start-up brand owner company assigns logistics provider to distribute its products within the country. Assigning distributors outside the country is a tactical reason as well and has other benefits such as brand ownership, facility planning and cost savings since such logistics company knows the internal rules and regulations and has broad experience in the field.

Generating cash and avoiding burden operating cost can be also a huge reason for mainly SMEs to outsource by transferring resources and allocating them/selling them to the outsourcer. Even when companies assign distributors they are effectively using their warehouses and stocking them with inventory therefore generating capital (Elmuti et al., 1998).

Although outsourcing could be of great benefits to companies, top management should have the right strategy of when and how to implement outsourcing since it has shown over the years that this process could be of failure to some companies especially nowadays that outsourcing is not looked at only for a cost saving perspective but also for a value-added function.

\subsection{Outsourcing Fails}

A lot of time companies fail in outsourcing and that is due to some major factors mentioned below, the concept has been evolving for about 200 years now if you include all types of outsourcing resulting in more complex process (Karthik, 2013a). 
Unclear objectives of outsourcing, most companies start the outsourcing brainstorming by putting down the reason for outsourcing and they start their list with a priority of cost saving as their main goal where in reality this is potentially their first mistake since cost reduction or saving should be the outcome not the key reason. Companies should realize the objective of outsourcing leading to gain competitive advantage, change of culture, functional restructuring and not pursue the cheapest solution with the aim to save on cost and deviate from the original concept of outsourcing.

Lack of communication, key element and most dangerous causing outsourcing to fail. It is important to establish regular source of communication with outsourcer not a reporting model since the communication can be easily replaced by reports, reviews and as long as the norms and metrics are good, there will a tendency not to talk to each other and this could of a disaster. Good communication is as good as frequent meetings, discussing project reports and progress. Having both done adequately is ultimate. Several factors could affect the communication such as cultural variation, language ability, even skills and technological competency (Karthik, 2013a).

Non accuracy of expectations, when partners don't set what is expected in terms of planning and implementation phases such as establishing tasks, tools, resources, clear system of communication, things could get expensive due to cost escalation and poor delivery of quality. The outsourcer should be equipped with detailed plans of what is needed and should understand the business drivers and roadmaps to deliver a good work and not be the blame for underperforming therefore jeopardize the business partnership.

No change in working environment, there some companies that outsource a department with functions, tasks, responsibilities, deliverables that are the same as existing in house or previously done as a function within the company. This happens frequently in marketing when companies outsource certain projects ideally that can be performed by the department where obviously this type of outsourcing will create tension and resistance to change. Outsourcing has to create value and getting rid of jobs does not always lower your cost even if the direct saving is of advantage, there are hidden intangible benefits for in house operations in some cases.

No factorization of risk Analysis, companies who fail in outsourcing don't usually factor the risks of having a provider who is unqualified, lacks resources or knowledge, lacks appropriate infrastructure, lacks dedicated resources or financial stability. A need to have thorough sets of criteria of selection to potential providers and ranking them is essential thus evaluating the list and choosing the appropriate provider with frequent evaluation in mind.

Other reasons for failure could be transition time which can result in poor performance and cost increase therefore ensuring your processes are ready for such implementation and resources availability are crucial factors to avoid failure. Another reason for failure is the inability to foresee cost rising or not to 
factor such risk in contracts to restrict third parties providers in loading growing costs to your bills. For instance, external factor such as hotels and airfare rates might rise up or the frequencies of movement of executives due to outsourcing needs, unemployment rate or inflation depending on the location of outsourced business (Karthik, 2013a).

Last but not least to mention is the buyer and provider behavior which can drive the relationship to failure. An example of failure could be micromanagement of companies seeking outsourcing due to discussed above reasons of poor communication, transition time, culture therefore a presence of micromanagement can easily destruct the partnership quite rapidly. A lot of time buyers change their needs and providers need to adapt to these changes therefore to prevent failure it is crucial that companies deal with providers as partners and share the potential changes to provide them with a flexibility degree of adaption (Karthik, 2013a).

\section{Types of Outsourcing}

\subsection{Logistics Outsourcing}

One of the main channels for outsourcing is logistics. Many companies still don't perceive this as a primary activity when outsourcing hence this may result in lower efficiency simply because this function is essential for companies who seek outsourcing and want to focus on the core business. As a matter of fact, this function is not a simple task, it involves logistics planning and execution, supply chain and in some cases implementation of lean manufacturing such as Just In Time while noting the complication from pick up to delivery electronically which derives the fact to treat it as a complete business unit in today's working environment. Some arguments with logistics outsourcing state that "logistics services outsourcing can also lead to improved information availability and security, reduce coordination and communication needs, faster transit times and, ultimately, an increased value added, income and competitive position" (Vissak, 2008).

Companies should consider logistics outsourcing to focus on core competencies, to minimize stock level, to reduce paperwork, to ameliorate activities of concerns, to gain know how from outsourcer, to improve Just In Time delivery, flexibility in shipping small amounts within reasonable time frame, to save on costs by handling and packing goods, to improve warehousing efficiency, to reduce and allocate personnel to other functions therefore improve the cash availability.

While few other arguments against logistics based on some studies articulate that "some companies avoid outsourcing as they resist to changes, dread complexity, are unaware of logistics service providers' capabilities and expertise, regard logistics too important to be outsourced and fear that carriers and third parties would be unable to provide the superior service the customers demand at a reasonable price" (Vissak, 2008). 
There are reasons as indicated to avoid logistics outsourcing which includes the growth of complexity within the group since people don't like changes, not enough study conducted on the third party logistics provider, inability for the outsourcer to provide superior service which increases customer complaints, complexity in delivering small customized quantities, reducing the workforce if applicable and its impact on employees, trust base relationship with fear of revealing relevant information by outsourcer.

\subsection{Intelligent Outsourcing}

Outsourcing has shown a great impact in the corporate field, companies are able to control cost, gain competitive advantage and sustain profitability, no questions asked.

Moving forward beyond traditional outsourcing, top companies are foreseeing ways to ameliorate the status quo reinventing the business model and recognizing the real power of intelligent outsourcing through innovations, deeper relationship with provider, identify for instance how companies need to retain competitive core and sustain the ability to compete in fast moving environment and unpredictable markets (Bajec \& Jakomin, 2011).

The idea is to establish differentiation which results in higher level of innovations, processes building whether core (non-direct) or non-core. It is basically a continuity of traditional outsourcing with more focus on win-win scenario, long term commitment and a bilateral relationship where the company saves on capital, reduce risks ultimately and improve the quality of operations. At the same time, the service provider improves service capacity, generate business profitable to leverage some room for improvement.

The importance of intelligent outsourcing becomes an essential element when competitors start seeking outsourcing therefore achieving similar results. Intelligent outsourcing comes in the play to support business growth, capacity analysis and ultimate capability determination. As mentioned previously that intelligent outsourcing complete the process of traditional outsourcing and therefore add to cost savings the element of innovations and its implication on how to improve the status quo. It looks at the value chain as a whole instead of focusing only on operations. Instead of creating only uniform processes, it adds differentiation in order to make it unique and hard to imitate. Intelligent outsourcing focuses on strategic excellence where it aligns operations when markets are shifting instead of improving only when markets are predictable. Provider defines things that companies are not aware of instead of working on what is presented or known by such company. Provider acts as a partner through leadership and innovation continuously from technology change instead of getting affected by it (Bajec \& Jakomin, 2011).

\section{Outsourcing and Backsourcing}

Before based on value chain analysis and for illustration purposes below are few 
cases where companies scored successes in outsourcing and few others drew back from outsourcing (back sourcing) due to unseen/unpredictable cost which became overburden to overcome.

A successful case is when Federal Express changed its primary activity by reconfiguring outbound logistics with the aim to ameliorate overnight deliveries. The company aligned as a secondary activity the process of human resources management to ease out the outcomes of reconfiguration. This case identifies the harmonization of primary and secondary activities. Another case is when Dell computers took advantage of outsourcing and contracted with third party provider outsourcing most of its customer service activities while the company focused on just in time inventory model and online distribution system with end results of sustaining competitive gain noting it was hard for competitors to imitate such process or even substitute such an innovation (Ranjith \& Bijuna, 2013).

The next couple cases present companies that used Back Sourcing. For illustration JP Morgan Chase signed a contract with IBM to outsource its IT services with the initial aim to improve innovation and save on costs. The firm incurred huge costs which were unforeseen obviously resulting in terminating the deal. Another case is when Diebold (ATM, voting machine and security systems) signed a seven-year contract with Deloitte outsourcing its IT services implementing an ERP system by Oracle. On the $4^{\text {th }}$ year, Diebold has incurred an enormous additional high cost where the company concluded that outsourcing did not meet the development of capabilities expected therefore terminated the contract (Ranjith \& Bijuna, 2013).

\section{Unconventional Outsourcing in Lebanon}

While Karthik argues that outsourcing has benefits and at the same time could cause failure, it is important to state the following cases facing the small Lebanese firms.

Companies facing shortage in cash, unavailability of resources, facilities can find themselves unable to perform so they think of outsourcing not only for support such as auditing and advertising but also outsourcing core functions.

High Pressure Processing (HPP) is a way in food where companies are outsourcing the core production functions and this process can replace additives and preservatives need for such products. It is a sophisticated process yet expensive for SMEs even large companies to pursue and it has been an outsourcing practice for many companies since it requires a lot of capital yet the core need is to focus on other core function like manufacturing standard products instead of learning and pursue a complicated process (Duffy, 2019).

In America, the cost of operating HPP is not only the procurement of machining. It requires a lot more from operations including maintenance, capacity requirements, optimizing both efficiency and effectiveness, facility planning and labor know-how so prior to making any decision on whether to outsource to 
HPP for instance, companies need to examine many elements if operations at first can be handled in house such as downtime which can be substantial like $10 \%$, preventive maintenance, meeting capacity so equipment won't be idle for some time, necessary staff to support operations (Duffy, 2019).

Lebanese companies and brand owners in Lebanon are outsourcing at the early stage the production of its food packaging products while owning the recipe. Agreements with different local and international manufacturing companies are being signed with full confidentiality and non-disclosure. Upper management is claiming that this strategic decision is cost-effective for them simply because of many issues the sector is facing including high cost of operations in terms of variable cost such as double electricity billing, energy and water billing, internet and telecommunication, increase in taxation and lack of governmental support in terms of infrastructure.

Upper management officials in SMEs are also claiming that the game is in packaging in terms of design the package, ease of open, following trends in food are usually their concerns and it's becoming the core concerns rather than secondary concerns.

It is becoming their main added value since they are saving on the COGS when they outsource the production and concentrate on the actual product (the whole) rather than the core product (the food content). Mediterranean packaged food in particular organic products is no secret production so small firms are taken advantage of the economical need, the overheads of the large manufacturer and saving on the cost since larger firm are being little more lean, can stock access of inventory and they have easier access to suppliers therefore better costing per SKU.

The below graph (Figure 1) represents a gap analysis and improvement in deliverables when core elements are being outsourced as a case study for an SME firm in Lebanon

Outsourcing core functions for small firms in Lebanon according to upper managers especially in the Mediterranean food packaging are becoming essential elements of survival especially in cases where companies are start-ups and need the capital to improve on the operations and have solid penetration strategy in different regional market.

\section{Core Functions Outsourcing}

Assigning distributors outside the country is also a tactical reason as well and have other benefits such as brand ownership, facility planning and cost savings since such logistics company knows the internal rules and regulations of that country and therefore have broad experience in the field.

A brand owner can effectively outsource not only the logistics and the distribution of its products but also the production of its food packaging products while owning the brand name. For the sake of argument and filling the gap, this would be an example of how outsourcing can benefit at first a given company (start-up or SME) and the economic sector in general. 


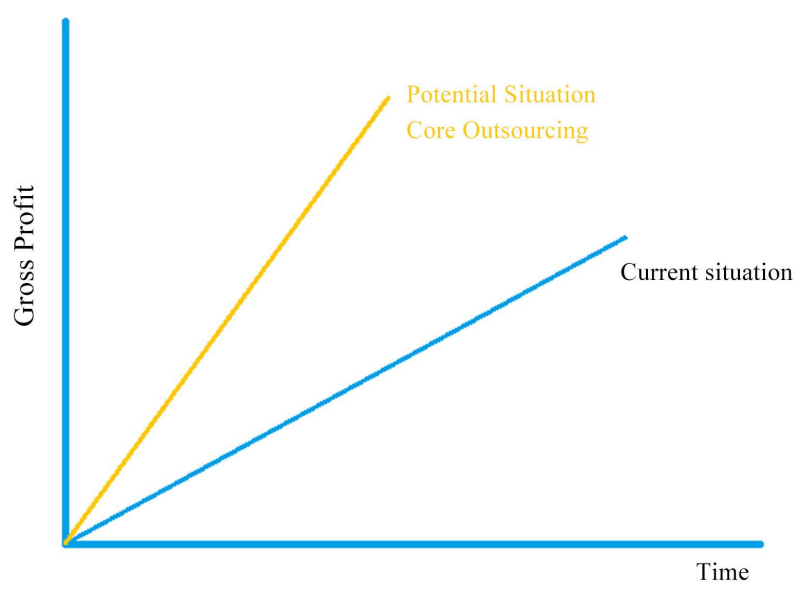

Figure 1. Lebanese Mediterranean packaged food outsourcing.

According to Lebanese owners and managers of SMEs, core outsourcing would work better when the following factors are present:

- The core function or the production of goods are not unique or special technology therefore it is not rocket science for the other manufacturer especially if it is organic where no additives or preservatives are being mixed.

- The production of goods is not at ultimate efficiency meaning no practices of lean, world class, JIT or waste management.

- The variable costs are expensive and the infrastructure is weak which is the case in Lebanon.

- The added value of the actual products is not only in the core or the content of the food part but rather in the packaging, label or brand name (the whole actual product).

- The capacity of local set-up is not sufficient for customer demand increase.

- The cost of raw material is high and not available during the season therefore must be shipped as refrigerated from regional countries.

- The market of the Mediterranean packaged food is way higher in demand outside Lebanon than the inside.

\section{Conclusion}

This study shows that outsourcing can help companies gain competitive advantage over competitions but also in some cases outsourcing can fail if elements such as innovation, differentiation from rivals and value creation are not considered.

Outsourcing is not always a long term plan, it could be short term or even tactical weekly plan as long as planning exists, pre-initiation activities such as benchmarking, business shifts, gathering and validating ideas, making sure all business tools and methods such as customer feedback, gap analysis and risk management are performed (Boguslauskas \& Kvedaraviciene, 2008).

Companies need to spend enough time evaluating decisions pertaining to outsourcing with value chain in mind, identifying relatively the importance of 
primary and secondary activities pertaining to companies seeking successful outsourcing.

The benefits of outsourcing can surpass any given company over competition by many means of achievements such as reducing cost, focusing on core competencies, improving supply chain and delivery time JIT, increasing customer satisfaction and obtaining satisfactory growth in profit. On the other hand, outsourcing can fail in some cases where companies incur huge costs in implementation, loose flexibility, face trust based issues with providers where relevant pertaining information becomes public.

This article tackled unconventional outsourcing in certain industries and certain cases when technology is not at best, products are not unique and can be easily produced by other entities. In order to gain deeper look at unconventional outsourcing practices, further research is needed to tackle unique products that require high level of knowledge and advanced technology.

As a conclusion there is a significant need for outsourcing but the decision of what, when, where and how to outsource must be well thought of especially the first part which is what to outsource since there is no room for a mistake at this stage (Boguslauskas \& vedaraviciene, 2009).

Further steps in decision making could hurt the company but could also be recoverable, the idea is to minimize risk of failure and attain a confidence level by analyzing well the value chain and selecting the right outsourcing partner and the right function to outsource.

\section{Conflicts of Interest}

The author declares no conflicts of interest regarding the publication of this paper.

\section{References}

Bajec, P., \& Jakomin, I. (2011). The Next Big Opportunity to Build Competitiveness: Intelligent Logistics Outsourcing. Transport Problems, 6, 41-50.

Boguslauskas, V., \& Kvedaraviciene, G. (2009). Difficulties in Identifying Company's Core Competencies and Core Processes. Engineering Economics, 62, 75-81.

Boguslauskas, V., \& Kvedaraviciene, G. (2008). Strategic Outsourcing Plan and the Structure of Outsourcing Process. Engineering Economics, 58, 60-66.

Raiborn, C., Butler, J., \& Massoud, M. (2009). Outsourcing Support Functions: Identifying and Managing the Good, the Bad, and the Ugly. Business Horizons, 52, 347-356. https://doi.org/10.1016/j.bushor.2009.02.005

Duffy, M. (2019). High Pressure Processing: Outsourcing vs. in House. National Provisioner, 233, 60-62.

Elmuti, D., Kathawala, Y., \& Monippallil, M. (1998). Outsourcing to Gain Competitive Advantage. Industrial Management, 40, 20-24.

Karthik, N. (2013a). Top 10 Reasons Why Outsourcing Fails.

http://www.outsourcing-center.com

Karthik, N. (2013b). Decreasing Delivery Headaches with Outsourcing Supply Chain 


\section{Management. http://www.outsourcing-center.com}

Ranjith, V. K., \& Bijuna, C. (2013). Outsourcing and Competitive Advantage. International Journal of Research in Commerce and Management, 4, 5.

Vissak, T. (2008). Management of Organizations: Achieving Success in Logistics Services. Systematic Research, 46, 149-162.

Zelinski, P. (2018). Outsourcing Phase Two. Modern Machine Shop, 90, 18. 